\title{
Food Traceability System: Current State and Future Needs of the Nigerian Poultry and Poultry Product Supply Chain
}

\author{
Hadiza Kabir Bako ${ }^{1}$, Munir Abba Dandago ${ }^{2}$, Sanusi Shamsudeen Nassarawa ${ }^{1}$ \\ ${ }^{1}$ Department of Food Science and Technology, Bayero University Kano, Kano, Nigeria \\ ${ }^{2}$ Department of Food Science and Technology, Kano University of Science and Technology, Kano, Nigeria
}

Email address:

shamsudeensunusi2015@gmail.com (S. S. Nassarawa)

\section{To cite this article:}

Hadiza Kabir Bako, Munir Abba Dandago, Sanusi Shamsudeen Nassarawa. Food Traceability System: Current State and Future Needs of the Nigerian Poultry and Poultry Product Supply Chain. Chemical and Biomolecular Engineering. Vol. 4, No. 3, 2019, pp. 40-44. doi: $10.11648 /$ j.cbe. 20190403.11

Received: May 31, 2019; Accepted: August 15, 2019; Published: December 25, 2019

\begin{abstract}
The study revealed a thriving Nigerian food industry and policymakers toward understanding food traceability systems in three ways. Firstly, a realistic strategy toward supply chain visibility. Secondly, verify the concept relating to the implementation of documentation and technological innovations. Thirdly, emphasized the significance of food safety and food recall taking into account current status and future needs and how a traceability system would be realized in the poultry sector by giving a clear roadmap for technology. Also the work explained the current state of the two most practiced method of poultry production; backyard and commercial scale was also investigated.
\end{abstract}

Keywords: Tracking, Farm, Production, Processing, Consumer, Retail and Distribution

\section{Introduction}

Food traceability is a role in logistics management that collects, keeps, and transmits sufficient data about a food, feed, food-producing animal or food constituent at all steps throughout the food journey so that it can be checked for safety and quality control, traced forward and tracked backwards at any given time [1] from farm to fork. It is part of strengthening relationships with consumers and giving them what they want, the ability to trust and understand what they are eating been it organic, vegetarian, kosher, halal or health-related required food. These Serious health concerns that have urge food manufacturers to change their handling approaches which lead to the alteration of food consumption habits. While most authorities have set methods and standards to ensure food quality and safety such as Hazard Analysis Critical Control Programs but food traceability is one aspect that is yet to receive serious attention.

Globally, food traceability systems have evolved over the years, and as firms incorporate the new technologies, these technologies have become a source of sustainable competitive benefit that would be hard to replicate by competitors [2]. Most countries have made traceability a mandatory procedure in the food industry although it varies between countries in Canada for example, no precise traceability regulations for food products; it only addresses livestock [3]. China is gradually establishing and updating national food safety laws and regulations with focus on entire food system. Food traceability was realized in Japan, through the collaboration of public and private sectors by addressing food safety issues using ICT. Also in the EU, motivation and scope of these rules cover sustainability and safety aspects for food and non-food products. While in Africa, participation in e-commerce has driven South Africa, Tanzania and Algeria to have a well-positioned automated traceable system in different areas of the food industry $[4,5]$. On the other hand, only but a few studies exist on food traceability from producers' point of view on poultry products.

This paper aims to contribute to the thriving Nigerian food industry and policymakers toward understanding food traceability systems in three ways. Firstly, a realistic strategy toward supply chain visibility. Secondly, verify the concept relating to the implementation of documentation and technological innovations. Thirdly, emphasized the significance of food safety and food recall taking into account current status and future needs and how a traceability 
system would be realized in the poultry sector by giving a clear roadmap for technology.

\section{Traceability System in Nigeria}

In Nigeria, the food supply chain and safety status are far from satisfactory according to the survey conducted by the Federal Ministry of Health in the study [6], although the Federal Ministry of Health (FMOH), Federal Ministry of Agriculture and Rural Development (FMARD), Federal Ministry of Environment (FMEvn), Federal Ministry of Science and Technology (FMST) and Federal Ministry of Investment, Trade and Industry (FMITI) have mandate food safety as far back as 1917 but, it reveals an outdated food safety system.

The impact of Food safety to public health and international trade cannot be overstressed. While poor agricultural practices of many food products have resulted in the international market refusing food products from Nigerian the likes of melon seeds and melon seed products, groundnuts and Shea fruits products because of their Aflatoxin contamination and unacceptable pesticide residue. Some of the problems that hinders improvement of food safety in the country include: ignorance of the social and economic significance of food safety, scarcity of information on outbreak incidence of food-borne disease, lack of knowledge of food safety and quality standards as outlined in international agreements, inability to enforce compliance with international standards and global best practices, inadequate and poor infrastructure and resources to support scientific risk analysis and upgrading of food safety regulatory systems, inefficient food supply chain and poor traceable system [6].

The poultry industry is one of the very lucrative of all in Nigeria's agricultural sector. It accounts for about $10 \%$ of agricultural GDP. The poultry population was estimated to be around 150.682 million of which $25 \%$ are commercially breed, $15 \%$ semi-commercially, and $60 \%$ backyard farmed. Consequently, livestock are vital source of good animal protein, contributing about $36.5 \%$ of the total protein intake of Nigerians. It was estimated to be worth of $\mathrm{N} 250$ billion and considered one of the greatest investment in agriculture. In 2011, Nigerian hen and egg production totaled $636,000 \mathrm{MT}$ and was valued at $\$ 527.49$ million, ranking 19th in the world and the top producer in Africa and poultry meat production was projected to be 450,000 MT by 2020 [7].

\subsection{Requirements of Traceability}

Globalization is an integral part of international food trade; it has exposed food supply and distribution chain to a risk of adulteration, bioterrorism, fraudulent and products of inferior-quality. These threats do not only imperil public health safety, but it also compromises environmental sustainability, erodes peoples trust, and cripples the food industry. With so much at stake, experts have acted tirelessly to strengthen safety standards and compliance. Food manufacturers and distributors have also realized new techniques and technologies to help avoid these hazards within the supply chain. Food traceability technology is a trail utilized to connect the gap between safety and compliance and has become a fundamental part of ensuring safe food within the supply chain [8]. The traceability technology, documentation and record keeping efficiently lowers the incidences of contamination in the food industries value chain by monitoring all the activities in the supply chain and indicating where quality control problem has transpired. For an efficient traceable system, the track-and-trace technology must be robust enough to store comprehensive information gathered from various occurrences, and be able to process information in real-time speed. If it breaks the interference would be felt within the entire supply chain from production to circulation, all the way down to delivery. In order that a food company is able to comply with food safety specifications and requirements, data collection and documentation are keys [9] although, only a few cooperation's have assessed traceability models that could be suitable across the whole food industry worldwide [10].

\subsection{Industry Implementation of Traceability}

The ISO 22005: 2007 specifies standards for traceability for feed and food chain and the fundamental and basic needs for industrial implementation and system design in ISO 22005: 2007 [11]. The aim is to identify a specific batch of food product and raw materials used in production [12] and then, follow that batch and each unit throughout the production and circulation line up to the final consumer. Hence a traceable system is based on three integral pillars of supply chain visibility [13]:

1. Outside traceability; specific product identification.

2. Within traceability; identity of raw materials and origin of final product.

3. Traceability at large; world unique identification.

Technological impact of traceability cannot be over emphases, one of the key factors in mitigating foodborne illness outbreaks is the ability to quickly identify the cause, source, and spread of the incident. This is exactly where traceability, food safety, and public health are linked. Therefore the implementation of tracking tool with identification and numbering standards (COOL) country of origin labeling regulations in accordance with ISO 22005: 2007 standards that specifies the principles and requirement for the design and implementation enactment of a feed and food traceability system is paramount. [14] Another important aspect is the mechanism for documentation. 
Table 1. Proposed possible implementation options of a traceable system.

\begin{tabular}{|c|c|c|}
\hline Implementation options & Methods/technology & Benefits \\
\hline \multirow{2}{*}{ Food identifier } & Delivery slips/invoices: manual inputs & $\begin{array}{l}\text { Direct and quick access to important attributes such as suppliers name, date of } \\
\text { production and expiry }\end{array}$ \\
\hline & Printed labels: ICT based technology & $\begin{array}{l}\text { Quicker access to information about the product in questions through electronic } \\
\text { database and tracking system }\end{array}$ \\
\hline \multirow{4}{*}{ Food trackers and tracers } & $\begin{array}{l}\text { Sensors and scanners } \\
\text { Barcodes }\end{array}$ & $\begin{array}{l}\text { Reduces product fraud by Collect sensed data from a physical or surrounding state } \\
\text { It have an economical alphanumeric codes that are fast to scan }\end{array}$ \\
\hline & RFID (radio-frequency identification) & $\begin{array}{l}\text { It allows products to be traced and monitored throughout the supply chain without } \\
\text { human intervention }\end{array}$ \\
\hline & WSN (wireless sensor network) & Gather information at a central location \\
\hline & Global positioning system & Monitors food product by its geographic location; i.e. site specification \\
\hline
\end{tabular}

\subsection{Food Safety and Product Recall and Withdrawal}

International Aspects of Food Safety Legislation has been realized through the activities of the Codex Alimentarius Commission, it specifies food standards, codes of practice, guidelines and other recommendations intended to protect public health and ensure fair trade practices [16]. The purpose of food recall is to protect public health by notifying consumers (where necessary) of harmful foodstuff by facilitating efficient, fast identification and removal of unsafe foodstuffs from the distribution line or market and to ensure that the hazardous food-products are rendered unsafe or destroyed [13].

Food Recall may include removal of unsafe food from distribution line and may involves notifying the consumers. Whereas Food Withdrawal may not include food sold to the consumer. In the Nigerian poultry industry, the most recent food recall were the alerts by The National Agency for Food and Drug Administration and Control (NAFDAC) in 2016 and 2017 which most poultry farms in where affected by the Avian Influenza (Bird Flu) resulting to destruction of millions of birds most of which were compensated for by the authorities.

\subsection{Case Study: Live Poultry, Meat Products and Egg}

The live poultry, poultry meat and egg sector have been selected as a case study because it is a system that involves large number of individuals; packers, supplier, distributors retail grocers and food service operators. Secondly, it is one industry that has responded to food recall and withdrawal as a result of the avian bird flu.

Figure 1 is a private owned farm that specializes in intensive commercial poultry production. From the interview conducted and site inspection it was observed that paper documentation was the method of traceability employed. Invoice number and quick book are used for easy traceability and account reconciliation.

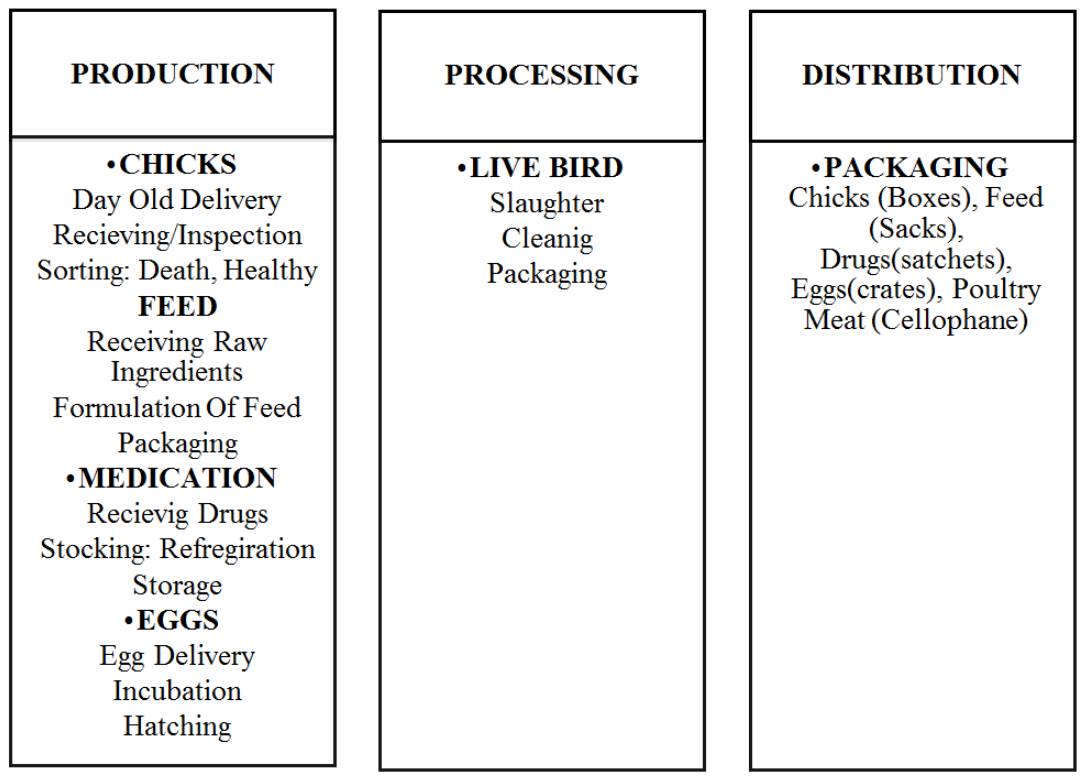

Figure 1. Farm A Flow of Activities.

Table 2. Farm B Flow of Traceability.

\begin{tabular}{lll}
\hline PRODUCTION & METHOD OF DOCUMENTATION & INPUT/OUTPUT DATA \\
\hline Receiving Egg & Waybill/invoice/receipt & Suppliers name, quantities, date, source \\
Inspection/incubation & Ledger & Breed, quantities, date \\
Sorting of hatched eggs & Register & Quantities, date \\
\hline
\end{tabular}




\begin{tabular}{lll}
\hline PRODUCTION & METHOD OF DOCUMENTATION & INPUT/OUTPUT DATA \\
\hline Breeding & Ledger & Quantities, death, duration \\
Sanitation & Register & Carried out by, type, date \\
Weighing/slaughter & Ledger & Batch, kill date, catch weight \\
Cleaning/packaging & Register/labels/barcode & Batch, quantities, breed, weight, kill date, expiring date \\
\hline
\end{tabular}

Table 2 is commercial producers of poultry meat. At all steps of the production process, no form of technology were used except for packaging of the processed product. Barcodes were generated and used on labels. Figure 2 is a backyard farm that breed chicken for egg and meat production on a small scale. Records kept are: Date of introduction of birds and quantities of eggs produced on the backyard farm.

It was found that at major steps along the production line of Figure 1, Table 2 and Figure 2 paper documentation were used. Electronic records were kept for accounting purposes
Figure 1 and Table 2. The information on the paper records include production journey, compliance certificates, and records of inspection. For instance; farms keep records of salmonella inspections, vaccination, and hygiene, origin of day old chick/fresh eggs, feed expenditures, and daily feeding routines. These information are available at the farms in case, of a problem needs to be investigated Figure 1 and Table 2 have no such records to reflect back on.

Nevertheless, in 2016, Farm a responded to the alert on Avian Influenza and all the birds were withdrawn from retail shops and live birds were destroyed.

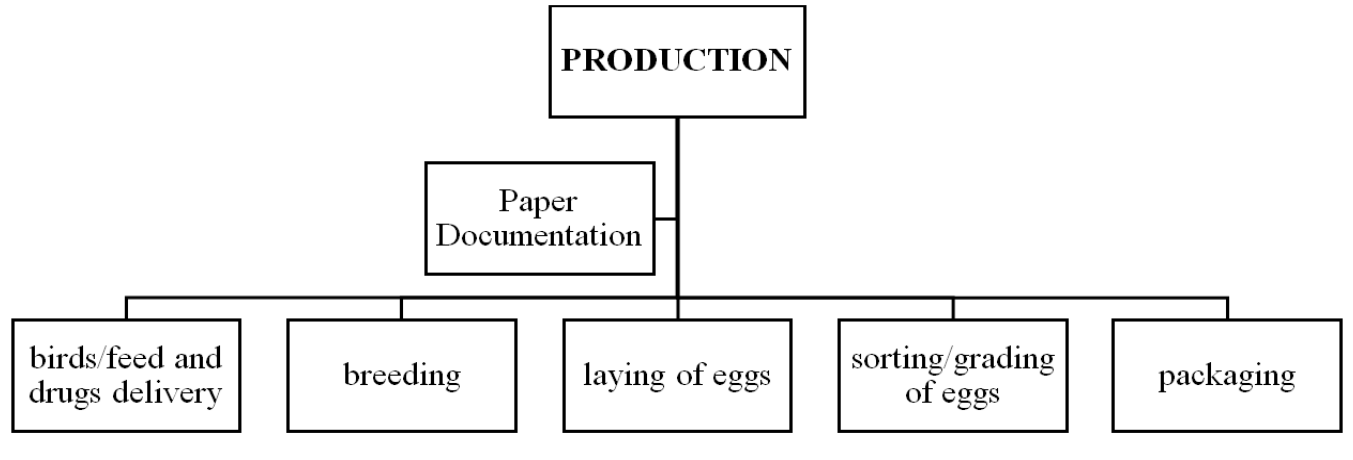

Figure 2. Farm C Flow of Traceability.

Some of the concerns expressed by the farmers for lack of digitization and atomization of the supply chain were:

1. Several middlemen, without integrity and sufficient knowledge of the global world.

2. Digitization, implementation and maintenance are often difficult which will result in highly price product.

Although change take time, it is suggested that some of the track and trace tools afore mentioned in Table 1 could be suitable for both commercial and backyard poultry production as they are low cost and back and forth traceability could be realized because manual paper documentation leads to human error.

\section{Future Prospects}

Food traceability systems impact efficiency, effective performance and opportunity to the food industry [17]. With the use of computer technology within the food quality systems it is possible to integrate a large data and automate the processes of food quality evaluation [18]. The trend to implementing traceability systems based on providing thorough documentation on the history of a food product may grow to create the need for traceability professionals in the food sector to develop low cost traceability technologies suitable for large and small scale farmers. Several technologies already exist in the poultry industry, for implementing traceable supply chains [19]. Future innovations in cryptography technology may be promising, it is said to be resistant to modification of data and the world economic forum describe [20]. It as digital ledger and a trust machine that is transparent, secure, decentralized and provides information of the food journey in real time speed [21] which can be accessible even with smart phone.

\section{Conclusion}

Safety and security are the essence of food traceability, globalization of the food market mounts pressure on the food industry and governments to provide a proper control of the quality of imported and exported food product. Based on our study, a traceable system has not yet been realized in the Nigerian poultry industry it shows and outdated system of which error and mistakes are bound to happen and, the following conclusions could be considered for implementation of a traceable system. In order to develop a traceable system and to accomplish a fully traceable line, a traceability procedure should be set for the complex processes and necessary information at every step along the line should be collected and shared.

It is necessary to creating a traceability system in response to disease risks this will reduce the risk of a public health concern within the food supply tracking and tracing can be achieved by integration of low cost traceability technique, recent innovation like block chain technology. Traceability in the Nigerian food industry particularly poultry and poultry products will provide a competitive edge in the global food 
market for food manufactures as the major challenge of the sector is deduced to be lack of digitization and automation making data retrieval back/forth slow. Therefore, the way forward is electronic data management systems and digitalization of the processes.

\section{Acknowledgements}

The authors wish to acknowledge the efforts of Anadariya farms and Sovet International farms for providing information necessary to carry-out this research.

\section{References}

[1] Badia-Melis, R., Mishra, P. and Ruiz-García, L. (2015) 'Food traceability: New trends and recent advances. A review', Food Control. Elsevier, 57, pp. 393-401. https://www.researchgate.net/publication/276454608_Food_Tr aceability_New_Trends_and_Recent_Advances_A_Review.

[2] Bosona, T. and Gebresenbet, G. (2013) 'Food traceability as an integral part of logistics management in food and agricultural supply chain', Food Control. Elsevier Ltd, 33 (1), pp.

32-48.https://www.researchgate.net/publication/257398985 F ood_traceability_as_an_integral_part_of_logistics_manageme nt in food and agricultural_supply_chain.

[3] Federal Ministry of Health Abuja Ngeria (2014) National Policy on Food Safety and Its Implementation Strategy. http://www.health.gov.ng/doc/FoodSafetyPolicy.pdf (Accessed: 18 October 2018).

[4] Flynn, D. (2013) 'The Changing World of Food Traceability'. http://www.foodsafetynews.com/2013/05/the-changing-worldof-food-chain-traceability/\#.Wzx5RdUzbIU.

[5] Gascó, M. and Gil-garcia, J. R. (2018) 'Providing Public Value through Data Sharing: Understanding Critical Factors of Food Traceability for Local Farms and Institutional Buyers', 9, pp. 2276-2285.

[6] Gillespie, J. R. and Flanders, F. B. Frank B. (2010) Modern livestock and poultry production. Delmar Cengage Learning. Available at: https://agriculturenigeria.com/farmingproduction/livestock/poultry (Accessed: 7 November 2018).

[7] Huang, Y., Whittaker, A. D. and Lacey, R. E. (2001) Automation for Food Engineering.

[8] Kim, H. M. and Laskowski, M. (2016) 'Towards an OntologyDriven Blockchain Design for Supply Chain Provenance', SSRN Electronic Journal. https://papers.ssrn.com/abstract=2828369Lawley, R., Curtis, L. and Davis, J. (2008) Food Safety Harzard. The Royal society of Chemistry.

[9] Liao, P., Chang, H. and Chang, C. (2011) 'Why is the food traceability system unsuccessful in Taiwan? Empirical evidence from a national survey of fruit and vegetable farmers', Food Policy. Elsevier Ltd, 36 (5), pp. 686-693. https://www.researchgate.net/publication/227418936_Why is the food_traceability_system_unsuccessful_in_Taiwan_Emp irical_evidence_from_a national_survey_of_fruit_and_vegeta ble_farmers_J.
[10] Moises, F., Epelbaum, B. and Garcia, M. (2014) 'Int. J. Production Economics The technological evolution of food traceability systems and their impact on fi $\mathrm{rm}$ sustainable performance : A RBV approach', Intern. Journal of Production Economics. Elsevier, 150, pp. 215-224. https://kar.kent.ac.uk/38341.

[11] Munro, T. (2018) How blockchain can improve food traceability. https://blog.matthews.com.au/how-blockchaincan-improve-food-traceability/ (Accessed: 7 November 2018).

[12] De Oliveira, C. A. F., Da Cruz, A. G., Tavolaro, P. and Corassin, C. H. (2016) 'Food Safety: Good Manufacturing Practices (GMP), Sanitation Standard Operating Procedures (SSOP), Hazard Analysis and Critical Control Point (HACCP)', Antimicrobial Food Packaging, (October), pp. 129-139. https://www.researchgate.net/publication/303414968_Food_Saf ety

[13] Opara, L. (2003). Traceability in agriculture and food supply chain : A review of basic concepts, technological implications, and future prospects', pp. 101-106.

[14] Psomas, E. L. and Kafetzopoulos, D. P. (2015) 'HACCP effectiveness between ISO 22000 certi fi ed and non-certi fi ed dairy companies', 53, pp. 134-139. https://www.infona.pl/resource/bwmeta1.element.elsevier5dfe92e5-950a-37fc-860d-79d281c05a26.

[15] Setboonsarng, S., Sakai, J. and Vancura, L. (2009) 'Food safety and ICT traceability systems: Lessons from Japan for developing countries'. Tokyo: Asian Development Bank Institute (ADBI) https://www.econstor.eu/handle/10419/53743 (Accessed: 15 November 2018).

[16] Tian, F. (2016) 'An Agri-food Supply Chain Traceability System for China Based on RFID \& Blockchain Technology', 2016 13th International Conference on Service Systems and Service Management (ICSSSM), pp. 1-6. http://ieeexplore.ieee.org/document/7538424/.

[17] Tian, F. (2017) 'A supply chain traceability system for food safety based on HACCP, blockchain \& Internet of things', 14th International Conference on Services Systems and Services Management, ICSSSM 2017 - Proceedings. https://ieeexplore.ieee.org/document/7996119/.

[18] Welt, B. and Blanchfield, J. R. (2012) 'Food Traceability', The International Union of Food Science and Technology, (March), pp. 1-14.

[19] World Health Organization (2008) Hazard analysis and critical control point generic models for some traditional foods A manual for the Eastern Mediterranean Region.

[20] Zhang, J. and Bhatt, T. (2014a) 'A Guidance Document on the Best Practices in Food Traceability', Comprehensive Reviews in Food Science and Food Safety. Wiley/Blackwell (10.1111), 13 (5), pp. 1074-1103 https://onlinelibrary.wiley.com/doi/abs/10.1111/15414337.12103 .

[21] Zhang, J. and Bhatt, T. (2014b) 'A Guidance Document on the Best Practices in Food Traceability', Comprehensive Reviews in Food Science and Food Safety, 13 (5), pp. 1074-1103. https://onlinelibrary.wiley.com/doi/abs/10.1111/15414337.12103. 